\title{
Understanding the Context of Health for Persons With Multiple Chronic Conditions: Moving From What Is the Matter to What Matters
}

\author{
Elizabeth A. Bayliss, MD, MSPH \\ Denise E. Bonds, MD, MPH \\ Cyntbia M. Boyd, MD, MPH \\ Melinda M. Davis, PbD \\ Bruce Finke, MD \\ Michael H. Fox, ScD \\ Russell E. Glasgow, PbD \\ Richard A. Goodman, MD, MPH \\ Suzanne Heurtin-Roberts, $P b D$ \\ Sue Lachenmayr, MPH, CHES \\ Cristin Lind, BA \\ Elizabetb A. Madigan, PbD, RN, \\ FAAN \\ David S. Meyers, MD \\ Suzanne Mintz, MS \\ Wendy J. Nilsen, PbD \\ Sally Okun, RN, MMHS \\ Sarab Ruiz, PbD \\ Marcel E. Salive, MD, MPH \\ Kurt C. Stange, $M D, P b D$

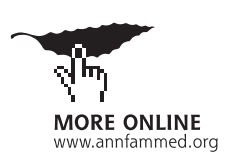

Conflicts of interest: authors report none.

\section{CORRESPONDING AUTHOR}

Kurt C. Stange, MD, PhD

Case Western Reserve University

11000 Cedar Ave, Suite 402

Cleveland, $\mathrm{OH} 44106$

kcs@case.edu

\begin{abstract}
PURPOSE An isolated focus on 1 disease at a time is insufficient to generate the scientific evidence needed to improve the health of persons living with more than 1 chronic condition. This article explores how to bring context into research efforts to improve the health of persons living with multiple chronic conditions (MCC).
\end{abstract}

\begin{abstract}
METHODS Forty-five experts, including persons with MCC, family and friend caregivers, researchers, policy makers, funders, and clinicians met to critically consider 4 aspects of incorporating context into research on MCC: key contextual factors, needed research, essential research methods for understanding important contextual factors, and necessary partnerships for catalyzing collaborative action in conducting and applying research.
\end{abstract}

RESULTS Key contextual factors involve complementary perspectives across multiple levels: public policy, community, health care systems, family, and person, as well as the cellular and molecular levels where most research currently is focused. Needed research involves moving from a disease focus toward a person-driven, goal-directed research agenda. Relevant research methods are participatory, flexible, multilevel, quantitative and qualitative, conducive to longitudinal dynamic measurement from diverse data sources, sufficiently detailed to consider what works for whom in which situation, and generative of ongoing communities of learning, living and practice. Important partnerships for collaborative action include cooperation among members of the research enterprise, health care providers, community-based support, persons with MCC and their family and friend caregivers, policy makers, and payers, including government, public health, philanthropic organizations, and the business community.

CONCLUSION Consistent attention to contextual factors is needed to enhance health research for persons with MCC. Rigorous, integrated, participatory, multimethod approaches to generate new knowledge and diverse partnerships can be used to increase the relevance of research to make health care more sustainable, safe, equitable and effective, to reduce suffering, and to improve quality of life.

Ann Fam Med 2014;260-269. doi: 10.1370/afm.1643.

\section{INTRODUCTION}

M ore than 1 in 4 Americans lives with the burden of more than 1 ongoing health condition, ${ }^{1-3}$ and the number of persons living with multiple chronic health conditions is growing dramatically. ${ }^{2,4}$ Medical costs for persons with chronic illnesses account for $75 \%$ of US health care spending ${ }_{1}{ }^{4}$ and more than $90 \%$ of the Medicare spending on older adults is devoted to persons suffering from multiple chronic conditions (MCC). ${ }^{5}$ This heavy expenditure has not yielded the desired increase in quality of life for those affected ${ }^{4} \mathrm{~A}$ strategic framework of the Department of Health and Human Services (DHHS) ${ }^{6}$ and multiple proposals and programs from the private sector highlight the growing concern about persons living with MCC. ${ }^{7}$ 
Current health care and research approaches are largely mismatched to the challenge of persons living with MCC. Both health care and research are primarily focused on single diseases. ${ }^{8,9}$ Most prevailing scientific approaches are designed to isolate objects of inquiry, controlling for potentially confounding contextual factors that are treated as noise to be muffled. Although reductionist research can yield useful information on the causes and consequences of single diseases, it is not well suited to addressing multifaceted problems, such as understanding the complex interaction of multimorbid chronic illnesses with social, environmental, and health care systems. ${ }^{10,11}$ Indeed, most randomized clinical trials ${ }^{12}$ and the evidence-based guidelines derived from them not only exclude persons with $\mathrm{MCC}_{1}{ }^{13}$ but attempt to hold contextual factors constant, thus contributing to evidence-based care that is fragmented and potentially harmful. ${ }^{14-16}$

Context involves the many factors that influence a person's life, from the biology of interacting diseases or treatments, to the values and life goals of the individual and family, the health and functioning of family and friend caregivers, and relevant health care system factors, community resources, and policies. These multilevel, ${ }_{1}^{17-21}$ complexly interacting factors are important for understanding MCC, for ensuring optimal benefit of preventive and therapeutic interventions, and for improving the lives of persons living with MCC.

As a result of fragmented, decontextualized research and health care, persons living with chronic illnesses, as well as their family and friend caregivers, often feel isolated and unsupported. Their health care is often splintered ${ }_{1}^{10,22,23}$ potentially dangerous, ${ }^{24-28}$ unguided by relevant scientific knowledge, ${ }^{13,29,30}$ and unsustainably expensive. ${ }^{31-37}$

The purpose of this article is to (1) identify domains of important contextual factors for research on MCC, (2) advance the research agenda, (3) recommend relevant research methods, and (4) suggest partnerships helpful for collaborative action. Its goal is better care and a higher quality of life for persons with MCC and their families and lower costs for society.

\section{METHODS}

In 2012, planning began to bring together a diverse group of expert stakeholders to address the need to incorporate context into research to improve the health of those living with MCC. Members of the planning group included representatives of the National Institutes of Health, the DHHS Office of the Assistant Secretary of Health, the Agency for Healthcare Research and Quality, the Centers for Disease Control and Prevention, the National Council on Aging, and the Patient-Centered Outcomes Research Institute. The planning process was guided by a logic model depicted in Figure 1, which shows how input from diverse participants, focused on 4 goal-directed activities, was hypothesized to lead to short-, intermediate- and longterm outcomes for persons living with MCC.

Forty-five invited experts met in Washington, DC, February 27-28, 2013, at the Patient-Centered Outcomes Research Institute. Participants were invited by

\section{Figure 1. Logic model guiding the multiple chronic conditions in context initiative.}

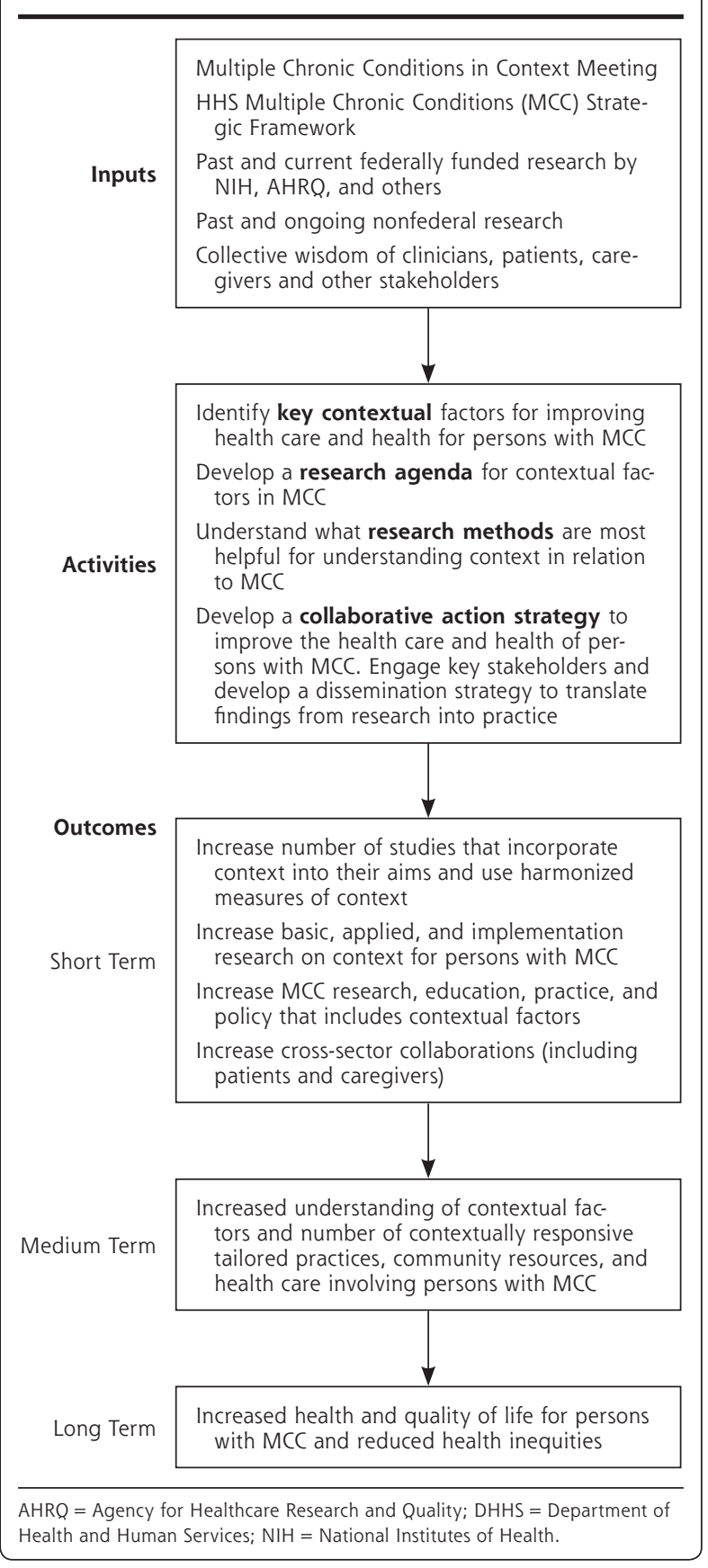


the planning committee to represent the experience of individuals with MCC, family and friend caregivers, researchers, funders, nongovernmental agencies, policy makers, clinicians, and health care system and public health specialists.

Participants were assigned to small working groups with diverse representation to examine critically the 4 topic areas: (1) key contextual factors, (2) needed research, (3) relevant research methods, and (4) partnerships for collaborative action. Each group summarized their work in writing and shared their findings with all participants in an iterative process designed to challenge and refine the emerging insights.

Subsequently, one meeting facilitator (K.C.S.) blended the group reports into a common document that was refined by group leaders, and the other meeting facilitator (W.J.N.) then iteratively honed by participants after the meeting.

\section{FINDINGS}

\section{Key Contextual Factors}

The complex interaction of contextual factors relevant for persons with MCC occurs at multiple levels, from policy to health care system, community, family, person, and the underlying biology. A multilevel classification of key contextual factor categories, selected subcategories, and examples are depicted in Table 1. The World Health Organization succinctly sums it up in the statement: "The context of people's lives determines their health." ${ }^{\prime 38}$

These multilevel contextual factors interact in complex ways to enhance or reduce health. ${ }^{39,40}$ Understanding and improving health and health care among persons with MCC therefore requires discerning which contextual factors are most relevant and ascertaining how these factors interact with each other to influence health or health care. ${ }^{41,42}$

Which contextual factors are most important varies with the person, time, and situation. This heterogeneity of contextual fac- tors is a conceptual and research challenge that requires understanding the health and health care of persons with MCC as a complex system in which contextual factors coevolve with time. ${ }^{42-49}$ Although it may seem simpler to ignore multilevel contextual factors, a constricted, disease-specific focus risks making misattributions about cause, effect, and intervention points of leverage in the complex and adaptive system of persons living with MCC. ${ }^{48}$ Identifying and then considering the most relevant factors from the domains of context outlined in Table 1 at all stages of the research process, from conceptualization to actualization to implementation and dissemination, and, finally, acting on the
Table 1. Multiple Levels and Examples of Key Contextual Factors

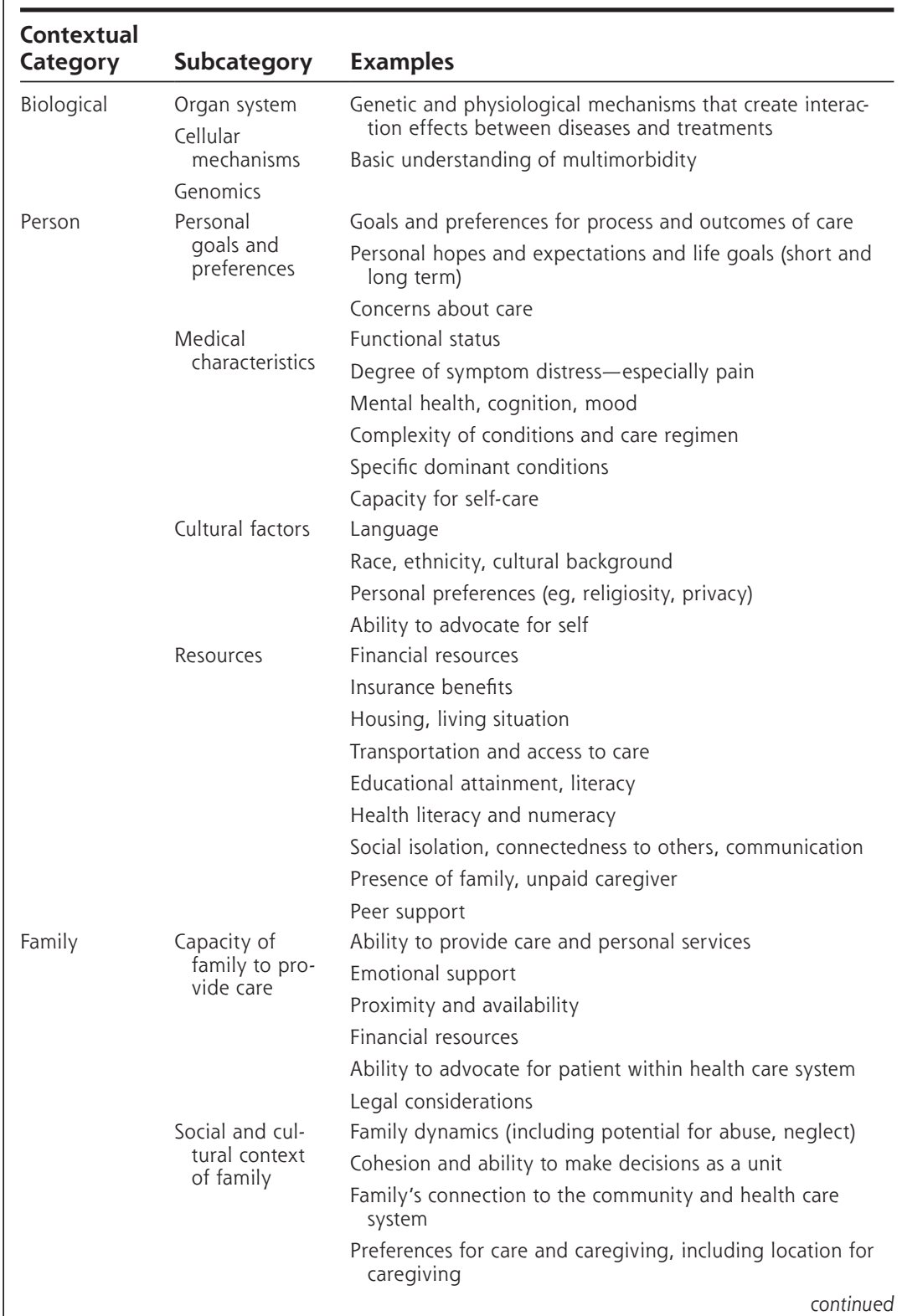


Table 1. Multiple Levels and Examples of Key Contextual Factors (continued)

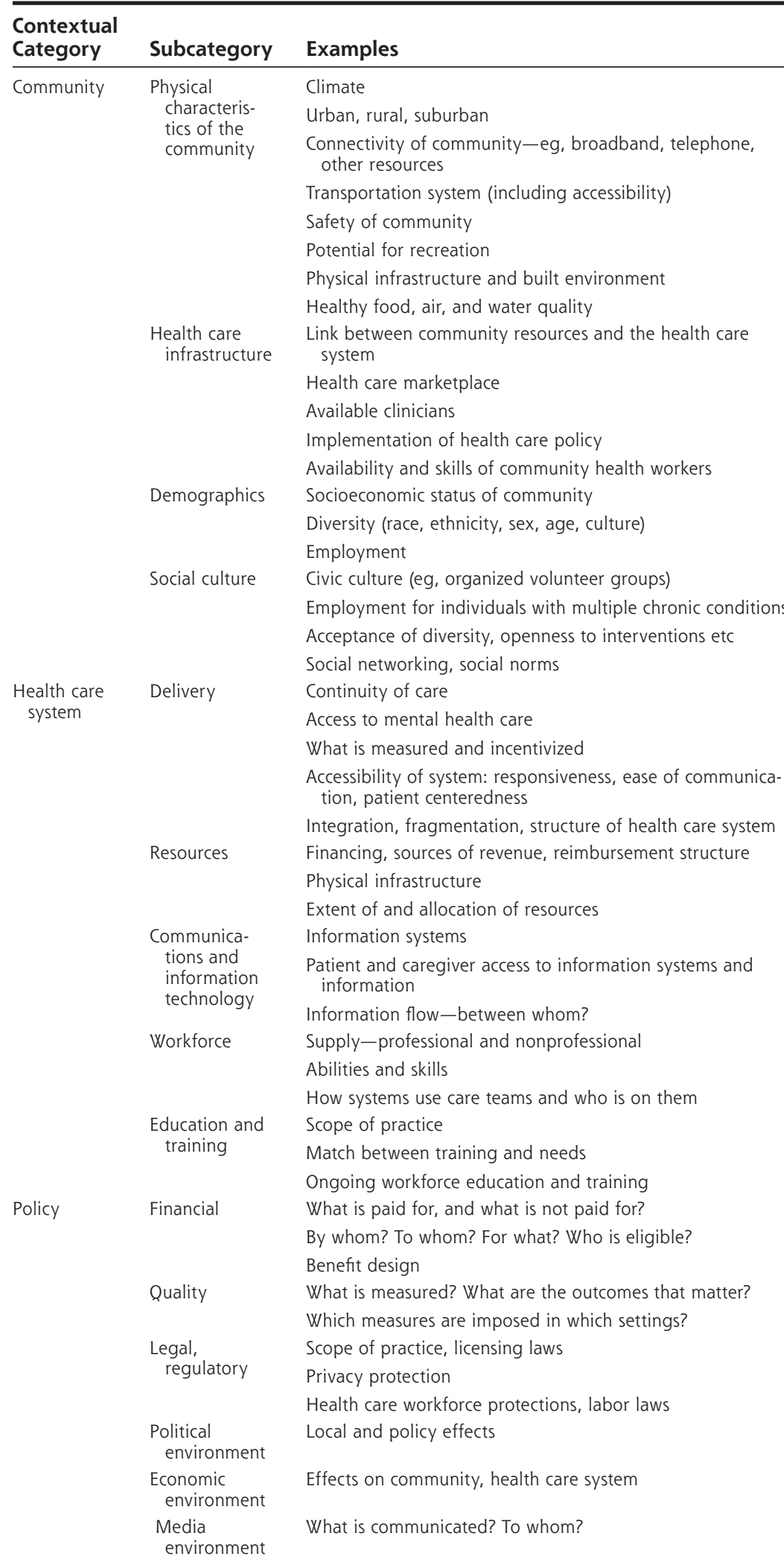

resulting hypotheses and understanding are needed to make research both rigorous in truly understanding the complexity of MCC, and relevant in focusing on what is most important.

\section{Advancing the Research Agenda}

Goal 4 of the DHHS strategic framework for optimum health and quality of life for individuals with MCC is to "facilitate research to fill knowledge gaps about, and interventions and systems to benefit, individuals with MCC." 6 The strategic framework suggests 4 main objectives: "increase the external validity of trials; understand the epidemiology of $\mathrm{MCC}_{i}$ increase clinical, community, and patient-centered health research; address disparities in MCC populations." ${ }^{\text {"6 The }}$ objectives that focus on external validity, patient-centeredness, and equity are highly consistent with the research foci identified in this article. Other helpful previous research agendas for MCC $^{50,51}$ have emphasized the medical context of the person.

Table 2 displays examples of important and context-based research questions that build on these agendas. These questions cluster around 2 important themes developed at the conference.

First is developing knowledge that moves beyond a diseasedriven research agenda ${ }^{9}$ to support health- and person-driven, ${ }^{52}$ goal-directed ${ }^{53,54}$ therapeutic and prevention strategies ${ }^{55}$ for persons with MCC. This effort involves shifting perspective from generating knowledge relevant for "... making sure the evidence-based commodities of care are delivered for each disease..." to systematic knowledge useful for "... assuring that persons with multiple illnesses get health care that helps them get on with what is important in 


\section{Table 2. Advancing the Research Agenda}

Developing contextualized knowledge to support health and person-driven, goal-directed care for persons with MCC How can the interacting effects of MCC on health be understood?

What are the mechanisms of interaction among relevant contextual factors and how do they affect health and health care?

What are the additive or multiplicative effects or burdens of living with or caring for multiple chronic illnesses?

What combinations of treatments, services, technologies, and resources help individuals reach their goals efficiently, effectively, and safely?

How can patients be supported in their self-management?

What are the diverse factors affecting personal goal setting and goal attainment?

What are practical and effective models for integrating mental and physical health?

How can effective models of rapid cycle knowledge generation be developed and implemented?

What can be learned from international comparisons?

What outcomes and measures are most relevant for persons with MCC and their caregivers?

What generalizable interventions are effective across different combinations of MCC?

What are the causes, duration, and severity of MCC in the population, what are the resulting disabilities, and which interacting aspects of context are most important for treatment effectiveness?

Achieving a culture, system, technology, and communities that facilitate person-driven, goal-directed care and selfmanagement that improves health

What approaches create a culture that supports the person-driven, goal-directed management of MCC?

What supportive systems and technologies are needed to improve the health and health care of persons with MCC?

How can the needed workforce, patient, family capacity, and peersupport be enhanced?

How do multidirectional linkages that include community resources affect the health and health care of persons with MCC?

How can we provide the needed training, organizational change, and team building?

What are effect of incentives through policy and reimbursement systems?

$\mathrm{MCC}=$ multiple chronic conditions.

their life." Relevant research questions include assessing specific contextual factors meaningful to different persons in different situations so that health care and health promotion can be focused on specific needs and goals.

The second theme relates to achieving the needed paradigm shift. The research questions here are about developing a culture, system, technology, and communities that facilitate person-driven, goal-directed care and self-management that improves health and well-being.

\section{Methods for Generating the Needed New Knowledge}

Because contextual factors change with time in ways that may affect outcomes, ${ }^{39,40}$ relevant contextual factors must be considered and assessed from conceptualization to completion and application of the research study. Methods need to be open to the possibility of emergence. They need to go beyond assumptions of linear effects and do more than assess central ten- dency. From a traditional clinical trials perspective, contextual factors would be considered as noise, ${ }^{56}$ as effect modifiers, or as confounding variables to be controlled or their effects made irrelevant through randomization. ${ }^{57-59}$ Decontextualized research methods, however, are a major reason why their findings are not translated into practice. ${ }^{60,61}$ They are not relevant to either patients or their clinicians. ${ }^{62-64}$

Considering context can cause diverse ontological and epistemological views of research, conceptual models, and analytic approaches to surface. ${ }^{65}$ Expanded research methods can be used to go beyond common reductionist conceptualizations to embrace new conceptual and computational models that include contextual factors. ${ }^{66}$ Methods that take context into account can help make sense of heterogeneity ${ }^{56}$ and of the frequent failure to replicate decontextualized studies in different settings. ${ }^{67-69}$ These methods can help to move beyond understanding what works on average to understanding what works for whom and in what situation. ${ }^{70,71}$

Table 3 lists current methodological challenges relevant to research on MCC and offers suggestions for contextualized research methods. This research requires methods that are participatory, multilevel, and flexible; are conducive to ongoing measurement from diverse (and sometimes innovative or novel) data sources, including existing data; ${ }_{i}$ assure study integrity integrate quantitative and qualitative methods; and generate ongoing learning. In addition, consideration of relationshipcentered principles, ${ }^{72,73}$ such as transparency and trustworthiness, responsiveness to concerns, early and consistent engagement, and openness to diverse perspectives, is necessary to ensure that research is informed by the perspectives of multiple stakeholders. ${ }^{74,75}$

These methods can contribute to a continuously learning health system ${ }^{76-78}$ that includes targeted populations, surrounding communities, and all stakeholders. The needed inclusive work is facilitated by developing a common lexicon across diverse stakeholders and by consistently requiring consideration of relevant contextual factors in funding proposals and journal reporting. ${ }^{79,80}$

\section{Partnerships for Collaborative Action}

The multilevel nature of contextual factors in MCC, along with the associated paradigm shift in research approach, requires partnership to generate, evaluate, and apply the needed new knowledge effectively in diverse settings and situations. Such collaborative action is consistent with recent calls by the NIH and others for team science ${ }^{81-83}$ and with the growing recognition of the need for multistakeholder partnerships to address complex multifactorial problems. ${ }^{49,84,85}$

Table 4 identifies suggested partners, domains in which their engagement is critical, and steps for their 
Table 3. Methods for Generating the Needed New Knowledge

\section{Current challenges}

There is not a common lexicon among stakeholders

Contextual factors are dynamic, fluid, interrelated, and vary according to perspective

Because contextual factors interact in dynamic ways, it is important to measure them from conceptualization to completion of the research study, and to have analytic techniques that do not rely on assumptions of linearity

To be relevant, methods may need to be combined, modified, or developed

There is tension between gathering data and burden to participants

\section{Suggestions for relevant knowledge generation}

Research studies involving MCC should always consider contextual factors

Contextualized MCC research requires methods that are:

Participatory (engage multiple perspectives and relevant partners)

Flexible (data collection, intervention delivery, outcomes ascertainment)

Both quantitative and qualitative (mixed methods)

Multilevel (from person to place to policy)

Sufficiently granular to address what works for whom in what situation

Conducive to ongoing measurement from diverse data sources

Generative of ongoing learning

In all aspects of research from conceptualization to dissemination and implementation:

Persons with MCC and their family and friend caregivers should participate

Researchers should effectively engage communities

Researchers should ensure that shared language is developed and used among stakeholders

Research funders and publishers' policies should require inclusion of contextual factors in all research, unless exclusion is justified

Context should be measured and analyzed at multiple levels

To reduce participant burden (eg, health care system, individuals, providers of health care), existing data (eg, EHR, marketing research, and public health data) should be mined when possible and commensurate compensation provided

Methods that are most appropriate to the research question should be selected, rather than having the methods drive the question. Exploration of methods from multiple disciplines (eg, occupational therapy, engineering, systems science, modeling) is encouraged

Development and adaptation of methods that are sensitive to the emergent properties of complex systems is warranted

$\mathrm{EHR}=$ electronic health record; $\mathrm{MCC}=$ multiple chronic conditions.

engagement. The changes required for research in MCC are both instrumental and part of a larger movement and political process; therefore, the requisite partnerships will also require a combination of incremental changes and movement toward a far-reaching, boundaryspanning ${ }^{86-88}$ new vision. Figure 2 depicts the necessary interactions across the spectrum of stakeholders generating the needed new knowledge, including payers and policy makers, community partners, patients and caregivers, the health care system, and research community.

The DHHS strategic framework for managing MCC $^{6}$ provides an important starting point for the needed collaborations, and it already has identi-

\section{Table 4. Partnership for Collaborative Action}

\section{Key collaborative partners}

Research enterprise (public and private, researchers and funders)

Health care providers, including those providing home care

Community-based support

Patients and their family and friend caregivers

Policy makers and payers

An array of other essential partners (eg, government public health, foundations)

\section{Domains of engagement for key partners}

Formulating research questions and methods that address context

Reporting and interpreting research findings with greater attention to context

Disseminating findings and strengthening the evidence base in prevention, management, and care for persons with MCC

Translating findings into plain language in the patient's context

Sustaining funding, advocacy, and other support for context in research and practice

Ongoing measurement and monitoring of progress and impact

Steps for building and sustaining collaborative partnership

Enumerate specific strategic partners

Establish common and compelling lexicons and stories

Engage partners

Foster innovation on context-informed research (eg, encourage funding announcements, FDA, IRBs to emphasize context-informed research)

Foster incorporation of context in practice (eg, cross-cutting clinical guidelines, performance measures, and patient-caregiver self-care management practice)

Continue reinforcing actions by partners

Measure and monitor effects and modulate actions

FDA = Federal Drug Administration; IRB = institutional review board; $\mathrm{MCC}=$ multiple chronic conditions.

\section{Figure 2. Partnerships for Collaborative Action}

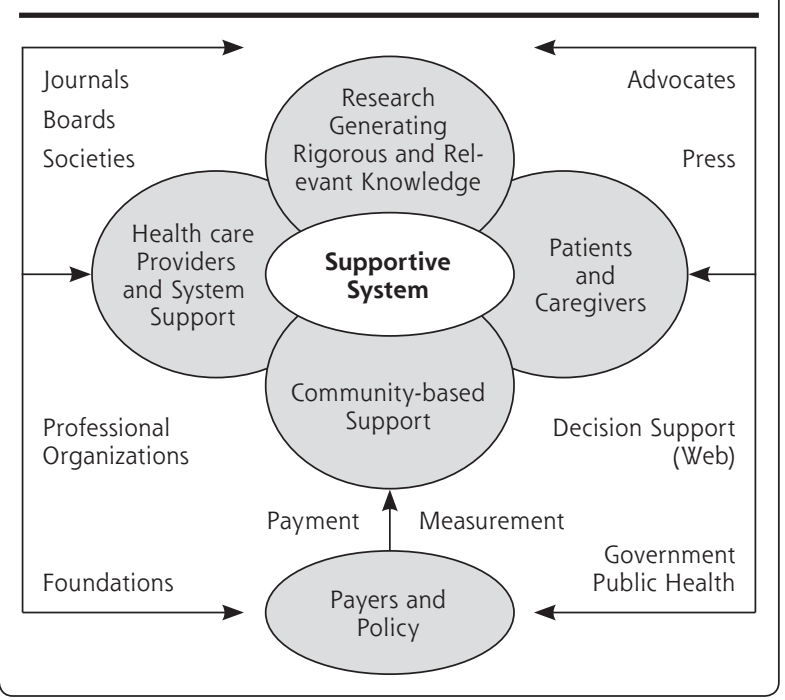

fied more than 250 programs, partners, and others working on aspects of the agenda. ${ }^{7}$ A more general framework for collaborative impact identifies 5 conditions of collective success: a common agenda, shared 
measurement systems, mutually reinforcing activities, continuous communication, and backbone supports. ${ }^{89}$ Using this framework, 5 short- to midterm recommendations emerge to support inclusion of key contextual factors in the initiatives:

1. Establish a measurement framework that includes a shared lexicon around priority contextual factors and indicators at the person, population, and system levels to monitor progress. The National Committee on Vital Health Statistics ${ }^{90}$ and the National Quality Forum ${ }^{91}$ would be logical homes for such efforts.

2. Build a national network of organizations interested in collecting and disseminating best practices in assessing and acting on context for persons with MCC. The national network would begin by identifying and build ing on current initiatives and identifying dissemination channels through which best practices can be shared.

3. Create a national public awareness campaign for consumers around key contextual factors. The campaign would build on emerging research and empower persons with MCC and their families to engage clinicians in contextual-based discussions that influence their care. (See the patient handout in the Supplemental Appendix.)

4. Activate and deploy a workforce that is skilled in incorporating context into research and practice. To do so will require the inclusion of contextualized understanding of MCC in the curriculum for health professionals and in training for early career scientists, as well as current researchers who need additional training in new methods and cross-cutting content. ${ }^{7}$

5. Develop a supportive policy environment. A broad-based coalition of private sector and government organizations is needed to think through policy options and help effect desirable policy changes as part of a long-term process of social change.

A longer term recommendation is to create an inventory and synthesis of interventions and best practices across all partner groups and convene a nationallevel entity (eg, an Institute of Medicine panel) to consider how contextual factors can be brought into research, implementation, and dissemination.

The fundamental premise among an emerging MCC-in-context collaborative is that government agencies, business, nonprofit organizations, and others can work together in a strategic, coordinated way to achieve ambitious societal goals focused on improving health and health care for those with multiple chronic illnesses while controlling health care costs.

\section{DISCUSSION}

Understanding contextual factors is vital to generating the new knowledge needed to improve the health of persons with MCC and to create a high-value health care system that is person-centered, goal-based, individualized, and sustainable. Such an effort will require a paradigm shift in how knowledge generation is understood and how research is conducted and implemented. The shift involves moving from a linear, reductionist view of the world to an understanding of the complexity of health and health care that is particularly apparent in persons with MCC.

The challenges to this work are substantial. Moving the research enterprise from a well-established and well-regarded reductionist approach that asks, "What is the matter?" to a research community that values context and asks, "What matters?" will require bold action by leaders within a research community supported and informed by persons with MCC, their family and friend caregivers, and clinicians. No group alone will be able to drive this movement forward. New coalitions and groups will need to form. Research and improvement efforts will need to be more congruent, so that contextualized knowledge generation and its application become part of the same learning community process.

New partnerships will involve researchers, clinicians, patients, caregivers, policy makers, and other stakeholders paying attention to contextual factors in generating questions, making observations, and doing interventions while continuing to learn during implementation, dissemination, and reinvention in new settings. ${ }^{92,93} \mathrm{New}$ policy initiatives will involve the development of infrastructure and relationships for real-time shared learning in research and practice. Funders and journal editors ${ }^{40,79,94}$ can play a prominent role in calling for context to be included in the research that is needed to take the science to next step by more closely linking research, practice, and the lived experience of persons with MCCs.

A focus on incorporating the perspectives of key stakeholders in research, especially persons with MCC, resonates with the mission of the new PatientCentered Outcomes Research Institute. ${ }^{95}$ It also aligns with the NIH focus on precision medicine ${ }^{96}$ that identifies key individual lever points to tailor interventions, as well as with growing initiatives around integrated care and care plans. ${ }^{32,54,97-99}$

The strengths of this report include findings generated by diverse stakeholder groups working together in an iterative process. Developing the working manuscript as a team provided an opportunity to bring together perspectives that are not usually apparent in the development of a research agenda, such as those of patients and family/friend caregivers, as well as community organizations and advocacy groups. The limitations of this article are that, despite its diversity, many stakeholders were not represented, and the results of our deliberations are only a first step in a large and 
diverse ongoing effort toward a more detailed blueprint for future action. Nevertheless, the meeting produced a set of principles for an ongoing inclusive process.

For those who have or who are at risk for MCC (which is almost everyone), developing an evidence base that includes context will ultimately lead to more integrated, effective, high value health care that is responsive to individual needs, preferences, and desires.

To read or post commentaries in response to this article, see it online at http://www.annfammed.org/content/12/3/260.

Key words: multiple chronic conditions; chronic illness; health services research

Submitted August 6, 2013; submitted, revised, December 24, 2013; accepted January 30, 2014.

Author affiliations: Kaiser Permanente, Denver, CO (Bayliss); National Heart, Lung and Blood Institute, Bethesda, MD (Bonds); Johns Hopkins University School of Medicine and Bloomberg School of Public Health, Baltimore, MD (Boyd); Oregon Health \& Sciences University, Portland, OR (Davis); Indian Health Services, Nashville, TN, and Baltimore, MD (Finke); Center for Disease Control and Prevention, Atlanta, GA (Fox); National Cancer Institute, National Institutes of Health, Bethesda, MD (Glasgow, Heurtin-Roberts); University of Colorado School of Medicine, Denver, CO (Glasgow); Office of the Assistant Secretary for Health, Department of Health and Human Services and Center for Disease Control and Prevention, Atlanta, GA (Goodman); National Council on Aging, Washington, DC (Lachenmayr, Ruiz); Patient/Caregiver Advocate, Boston, MA (Lind); Karolinska Institute, Stockholm, Sweden (Lind); Case Western Reserve, Cleveland, $\mathrm{OH}$ (Madigan, Stange); Agency for Healthcare Research and Quality, Rockville, MD (Meyers); Family Caregiver Advocacy, Kensington, MD (Mintz); Office of Behavioral and Social Sciences Research, National Institutes of Health, Bethesda, MD (Nilsen); PatientsLikeMe, Cambridge, MA (Okun); University of Chicago, Chicago, IL (Ruiz); National Institute on Aging, Bethesda, MD (Salive).

Contributors and groups: Project and conference facilitators: Wendy J. Nilsen, PhD, Office of Behavioral and Social Sciences Research, National Institutes of Health, Bethesda, MD, and Kurt C. Stange, MD, PhD, Case Western Reserve University, Cleveland, $\mathrm{OH}$.

Key contextual factors: Group leaders Elizabeth A. Bayliss, MD, MSPH, Kaiser Permanente, Denver, CO, and David Meyers, MD, Agency for Healthcare Research and Quality, Rockville, MD; Suzanne Mintz, Family Caregiver Advocacy, Kensington, MD; Josephine P. Briggs, $M D$, National Center for Complementary and Alternative Medicine, Bethesda, MD; Emily Dessem, National Council on Aging, Washington, DC; Giovanna Giuliani, MBA, MPH, California HealthCare Foundation, Oakland, CA; Shari Ling, MD, Center for Medicare and Medicaid Services, Baltimore, MD; Diane Meier, MD, Mt. Sinai Hospital, New York, NY; Steven Mintz, Patient/Caregiver Advocate, Kensington, MD; Joan D. Penrod, PhD, Centers for Medicare and Medicaid Services, Baltimore, MD; Michelle Washko, PhD, Center for Disability and Aging Policy, Administration for Community Living, Washington, DC.

Research methods: Group leader Denise E. Bonds, MD, MPH, National Heart, Lung and Blood Institute, Bethesda, MD, and Sally Okun, RN, MMHS, PatientsLikeMe, Cambridge, MA; Melinda M. Davis, PhD, Oregon Health $\&$ Sciences University, Portland, OR; Barbara L. Kornblau, JD, OTR, Patient/Caregiver Advocate, Washington, DC, and Florida AEM University, Tallahassee, FL; Emmanuelle St. Jean, National Council on Aging, Washington, DC.
Research agenda: Group leaders Cynthia M. Boyd, MD, MPH, Johns Hopkins University School of Medicine and Bloomberg School of Public Health, Baltimore, MD, and Marcel E. Salive, MD, MPH, National Institute on Aging/NIH, Bethesda, MD; Michael H. Fox, ScD, Center for Disease Control and Prevention, Atlanta, GA; Russell Glasgow, PhD, National Cancer Institute, Bethesda, MD, and University of Colorado School of Medicine, Denver, CO; Suzanne Heurtin-Roberts, PhD, National Cancer Institute, Bethesda, MD; Sue Lachenmayr, MPH, CHES, National Council on Aging, Washington, DC; Catherine Alfano, PhD, National Cancer Institute, Bethesda, MD; Lisa A. Cooper MD, MPH, Johns Hopkins University School of Medicine and Bloomberg School of Public Health, Baltimore, MD; Marisa Elena Domino, PhD, UNC Chapel Hill, Chapel Hill, NC; Robert Hornyak, MS, Administration on Community Living, Washington, DC; Lisa LeRoy, MBA, PhD, Abt Associates, Cambridge, MA; Alicia Richmond Scott, MSW, Office of the Assistant Secretary for Health, Department of Health and Human Services, Rockville, MD; Mary Tinetti, MD, Yale University, New Haven, CT.

Collaborative action: Group leaders Richard Goodman, MD, MPH, Office of the Assistant Secretary for Health, Department of Health and Human Services, and Center for Disease Control and Prevention, Atlanta, GA, and Sarah Ruiz, PhD, National Council on Aging, Washington, DC; Bruce Fink, MD, Indian Health Services, Nashville, TN, and Baltimore, MD; Cristin Lind, Patient/Caregiver Advocate, Boston, MA (currently at the Karolinska Institutet, Stockholm, Sweden); Elizabeth A. Madigan, PhD, RN, FAAN, Case Western Reserve University, Cleveland, $\mathrm{OH}$; Anne Beal, MD, MPH, Patient-Center Outcomes Research Institute, Washington, DC; Caroline Blaum, MD, MS, NYU Langone Medical Center, New York, NY; Gail Hunt, National Alliance for Caregiving-PCORI Board, Bethesda, MD; Keith Lind, JD, AARP, Washington, DC; Leon Purnell, Patient/Caregiver Advocate, Washington, DC; Joe Selby, MD, MPH, Patient-Center Outcomes Research Institute, Washington, DC; Michelle Spafford, National Council on Aging, Washington, DC.

Funding support: Dr Stange's time is supported in part by a Clinical Research Professorship from the American Cancer Society and by the National Cancer Society through the Intergovernmental Personnel Act.

Disclaimer: The findings and conclusions in this report are those of the authors and do not necessarily reflect the official position of the Centers for Disease Control and Prevention, National Institutes for Health, Agency for Healthcare Research and Quality, federal agencies, or other organizations of the authors or persons named in the above contributor groups.

Acknowledgments: The authors are grateful to the Patient-Centered Outcomes Research Institute, which hosted our meeting. Anand Parekh, $\mathrm{MD}, \mathrm{MPH}$, and Robert Kaplan, PhD, made helpful framing comments at the outset of our meeting.

- Supplementary materials: Available at http://www.AnnFamMed. org/content/12/3/260/suppl/DC1/

\section{References}

1. Anderson G, for the Robert Woods Johnson Foundation. Chronic care: making the case for ongoing care. 2010. http://www.rwjf.org/ content/dam/web-assets/2010/01/chronic-care. Accessed Jun 5, 2013.

2. Ward BW, Schiller JS. Prevalence of multiple chronic conditions among US adults: estimates from the National Health Interview Survey, 2010. Prev Chronic Dis. 2013;10:E65.

3. Machlin SR, Soni A. Health care expenditures for adults with multiple treated chronic conditions: estimates from the Medical Expenditure Panel Survey, 2009. Prev Chronic Dis. 2013;10:E63.

4. Institute of Medicine. Living Well with Chronic Illness: A Call for Public Health Action. Washington, DC: National Academy Press; 2012. 
5. Centers for Medicare \& Medicaid Services. Chronic Conditions among Medicare Beneficiaries, Chart Book. Baltimore, MD: CMS. Center for Strategic Planning; 2011. http://www.cms.gov/Research-StatisticsData-and-Systems/Statistics-Trends-and-Reports/Chronic-Conditions/ Downloads/2011Chartbook.pdf.

6. US Department of Health and Human Services. Multiple Chronic Conditions-A Strategic Framework: Optimum Health and Quality of Life for Individuals with Multiple Chronic Conditions. Washington, DC: US Department of Health and Human Services; 2010.

7. Department of Health and Human Services. Inventory of Multiple Chronic Conditions Activities Database of Programs, Tools, and Research Initiatives to Address the Needs of Individuals with Multiple Chronic Conditions. http://www.hhs.gov/ash/initiatives/mcc/mcc-inventory.html.

8. Stange KC. A science of connectedness. Ann Fam Med. 2009;7(5): 387-395.

9. Peek CJ, Baird MA, Coleman E. Primary care for patient complexity, not only disease. Fam Syst Health. 2009;27(4):287-302.

10. Stange KC. The problem of fragmentation and the need for integrative solutions. Ann Fam Med. 2009;7(2):100-103.

11. Barnett K, Mercer SW, Norbury M, Watt G, Wyke S, Guthrie B. Epidemiology of multimorbidity and implications for health care, research, and medical education: a cross-sectional study. Lancet. 2012;380(9836):37-43.

12. Zulman DM, Sussman JB, Chen X, Cigolle CT, Blaum CS, Hayward RA. Examining the evidence: a systematic review of the inclusion and analysis of older adults in randomized controlled trials. J Gen Intern Med. 2011;26(7):783-790.

13. Fortin M, Dionne J, Pinho G, Gignac J, Almirall J, Lapointe L. Randomized controlled trials: do they have external validity for patients with multiple comorbidities? Ann Fam Med. 2006;4(2):104-108.

14. Cebul RD, Rebitzer JB, Taylor LJ, Votruba M. Organizational fragmentation and care quality in the U.S. health care system. NBER Working Paper. 2008; 14212. http://www.nber.org/papers/w14212. Accessed Jul 12, 2010.

15. Liu CW, Einstadter D, Cebul RD. Care fragmentation and emergency department use among complex patients with diabetes. Am J Manag Care. 2010;16(6):413-420.

16. Stange KC. The paradox of the parts and the whole in understanding and improving general practice. Int I Qual Health Care. 2002; 14(4):267-268.

17. Stange KC, Breslau ES, Dietrich AJ, Glasgow RE. State-of-the-art and future directions in multilevel interventions across the cancer control continuum. J Natl Cancer Inst Monogr. 2012;2012(44):20-31.

18. Schensul JJ. Community, culture and sustainability in multilevel dynamic systems intervention science. Am J Community Psychol. 2009:43(3-4):241-256.

19. Engel GL. The need for a new medical model: a challenge for biomedicine. Science. 1977;196(4286):129-136.

20. Engel GL. The clinical application of the biopsychosocial model. Am J Psychiatry. 1980;137(5):535-544.

21. Borrell-Carrió F, Suchman AL, Epstein RM. The biopsychosocial model 25 years later: principles, practice, and scientific inquiry. Ann Fam Med. 2004;2(6):576-582.

22. Hughes JR, Grayson R, Stiles FC. Fragmentation of care and the medical home. Pediatrics. 1977;60(4):559.

23. Kathol R, Saravay SM, Lobo A, Ormel J. Epidemiologic trends and costs of fragmentation. Med Clin North Am. 2006;90(4):549-572.

24. Weiner SJ, Schwartz A, Weaver F, et al. Contextual errors and failures in individualizing patient care: a multicenter study. Ann Intern Med. 2010;153(2):69-75.

25. LaCombe MA. Contextual errors. Ann Intern Med. 2010;153(2): 126-127.

26. Hoff TJ. How work context shapes physician approach to safety and error. Qual Manag Health Care. 2008;17(2):140-153.

27. Borrell-Carrió F, Epstein RM. Preventing errors in clinical practice: a call for self-awareness. Ann Fam Med. 2004;2(4):310-316.
28. National Research Council of the National Academies. Making the Nation Safer: The Role of Science and Technology in Countering Terrorism. Washington, DC: National Academies Press; 2002.

29. Tinetti ME, Bogardus ST Jr, Agostini JV. Potential pitfalls of diseasespecific guidelines for patients with multiple conditions. N Engl J Med. 2004;351(27):2870-2874.

30. Tinetti ME, Fried T. The end of the disease era. Am J Med. 2004; 116(3):179-185.

31. Fortin M, Dubois MF, Hudon C, Soubhi H, Almirall J. Multimorbidity and quality of life: a closer look. Health Qual Life Outcomes. 2007;5(1):52.

32. Boult C, Wieland GD. Comprehensive primary care for older patients with multiple chronic conditions: "Nobody rushes you through". JAMA. 2010;304(17):1936-1943.

33. Bayliss EA, Bosworth HB, Noel PH, Wolff JL, Damush TM, Mciver L. Supporting self-management for patients with complex medical needs: recommendations of a working group. Chronic Illn. 2007;3(2):167-175.

34. Bayliss EA, Edwards AE, Steiner JF, Main DS. Processes of care desired by elderly patients with multimorbidities. Fam Pract. 2008; 25(4):287-293.

35. Fortin M, Soubhi $H$, Hudon C, Bayliss EA, van den Akker M. Multimorbidity's many challenges. BMJ. 2007;334(7602):1016-1017.

36. Bayliss EA, Steiner JF, Fernald DH, Crane LA, Main DS. Descriptions of barriers to self-care by persons with comorbid chronic diseases. Ann Fam Med. 2003;1(1):15-21.

37. Bayliss EA, Ellis JL, Steiner JF. Barriers to self-management and quality-of-life outcomes in seniors with multimorbidities. Ann Fam Med. 2007;5(5):395-402.

38. World Health Organization. The determinants of health. http://www. who.int/hia/evidence/doh/en/. Accessed Jun 11, 2013.

39. Tomoaia-Cotisel A, Scammon DL, Waitzman NJ, et al. Context matters: the experience of 14 research teams in systematically reporting contextual factors important for practice change. Ann Fam Med. 2013;11(Suppl 1):S115-S123.

40. Stange KC, Glasgow RE. Considering and reporting important contextual factors in research on the patient-centered medical home. 2013. AHRQ Publication No. 13-0045-EF.

41. Valderas JM, Starfield B, Sibbald B, Salisbury C, Roland M. Defining comorbidity: implications for understanding health and health services. Ann Fam Med. 2009;7(4):357-363.

42. Plsek PE, Greenhalgh T. Complexity science: The challenge of complexity in health care. BMJ. 2001;323(7313):625-628.

43. Thomas P. Applying complexity theory to primary health care organizations In: Kernick D, ed. Complexity and Healthcare Organization. A View from the Street. Abingdon: Radcliffe Medical Press; 2004:323-334.

44. Upshur REG, Tracy S. Chronicity and complexity: Is what's good for the diseases always good for the patients? Can Fam Phys. 2008; 54(12):1655-1658.

45. Wilson T, Holt T, Greenhalgh T. Complexity science: complexity and clinical care. BMJ. 2001;323(7314):685-688.

46. Cohn S, Clinch M, Bunn C, Stronge P. Entangled complexity: why complex interventions are just not complicated enough. J Health Serv Res Policy. 2013;18(1):40-43.

47. Diez-Roux AV. Multilevel analysis in public health research. Annu Rev Public Health. 2000;21:171-192.

48. Heath I, Rubenstein A, Stange KC, van Driel M. Quality in primary health care: a multidimensional approach to complexity. BMJ. 2009;338:b1242.

49. Leischow SJ, Best A, Trochim WM, et al. Systems thinking to improve the public's health. Am J Prev Med. 2008;35(2)(Suppl):S196-S203.

50. Norris SL, High K, Gill TM, et al. Health care for older Americans with multiple chronic conditions: a research agenda. J Am Geriatr Soc. 2008;56(1):149-159.

51. Boyd CM, Ritchie CS, Tipton EF, Studenski SA, Wieland D. From Bedside to Bench: summary from the American Geriatrics Society/National Institute on Aging Research Conference on Comorbidity and Multiple Morbidity in Older Adults. Aging Clin Exp Res. 2008;20(3):181-188. 
52. Peek CJ. Integrating care for persons, not only diseases. J Clin Psychol Med Settings. 2009;16(1):13-20.

53. Mold JW, Blake GH, Becker LA. Goal-oriented medical care. Fam Med. 1991;23(1):46-51.

54. Reuben DB, Tinetti ME. Goal-oriented patient care-an alternative health outcomes paradigm. N Engl J Med. 2012;366(9):777-779.

55. Wallace RB, Salive ME. The dimensions of multiple chronic conditions: where do we go from here? A commentary on the Special Issue of Preventing Chronic Disease. Prev Chronic Dis. 2013;10:E59.

56. Davidoff F. Heterogeneity is not always noise: lessons from improvement. JAMA. 2009;302(23):2580-2586.

57. Berkman LF. Social epidemiology: social determinants of health in the United States: are we losing ground? Annu Rev Public Health. 2009;30:27-41.

58. Fortin M, Bravo G, Hudon C, et al. Relationship between multimorbidity and health-related quality of life of patients in primary care. Qual Life Res. 2006;15(1):83-91.

59. Ovretveit JC, Shekelle PG, Dy SM, et al. How does context affect interventions to improve patient safety? An assessment of evidence from studies of five patient safety practices and proposals for research. BMJ Qual Saf. 2011;20(7):604-610.

60. Bradley EH, Webster TR, Baker D, et al. Translating Research into Practice: Speeding the Adoption of Innovative Health Care Programs. New York, NY: The Commonwealth Fund; July 2004.

61. Feldstein AC, Glasgow RE. A practical, robust implementation and sustainability model (PRISM) for integrating research findings into practice. Jt Comm J Qual Patient Saf. 2008;34(4):228-243.

62. Fagnan LJ, Handley MA, Rollins N, Mold J. Voices from left of the dial: reflections of practice-based researchers. J Am Board Fam Med. 2010;23(4):442-451.

63. Mercer SL, DeVinney BJ, Fine LJ, Green LW, Dougherty D. Study designs for effectiveness and translation research :identifying tradeoffs. Am J Prev Med. 2007;33(2):139-154.

64. Rothwell PM. External validity of randomised controlled trials: "to whom do the results of this trial apply?". Lancet. 2005;365(9453): 82-93.

65. Thomas P. General medical practitioners need to be aware of the theories on which our work depend. Ann Fam Med. 2006;4(5):450-454.

66. Goodman RA, Posner SF, Huang ES, Parekh AK, Koh HK. Defining and measuring chronic conditions: imperatives for research, policy, program, and practice. Prev Chronic Dis. 2013;10:E66.

67. Christensen CM, Baumann H, Ruggles R, Sadtler TM. Disruptive innovation for social change. Harv Bus Rev. 2006;84(12):94-101, 163.

68. Grimshaw JM, Thomas RE, MacLennan G, et al. Effectiveness and efficiency of guideline dissemination and implementation strategies. Health Technol Assess. 2004;8(6):iii-iv, 1-72.

69. McLaren L, Ghali LM, Lorenzetti D, Rock M. Out of context? Translating evidence from the North Karelia project over place and time. Health Educ Res. 2007;22(3):414-424.

70. Pawson R, Tilley N. Realistic Evaluation. London, England: Sage Publications Ltd; 1997.

71. Pawson R, Greenhalgh T, Harvey G, Walshe K. Realist review-a new method of systematic review designed for complex policy interventions. J Health Serv Res Policy. 2005;10(Suppl 1):21-34.

72. Beach MC, Inui T; Relationship-Centered Care Research Network. Relationship-centered care. A constructive reframing. J Gen Intern Med. 2006;21(Suppl 1):S3-S8.

73. Epstein RM, Fiscella K, Lesser CS, Stange KC. Why the nation needs a policy push on patient-centered health care. Health Aff (Millwood). 2010;29(8):1489-1495.

74. Hibbard JH. Community-based participation approaches and individual health activation. J Ambul Care Manag. 2009;32(4):275-277.

75. Macaulay AC, Commanda LE, Freeman WL, et al; North American Primary Care Research Group. Participatory research maximises community and lay involvement. BMJ. 1999;319(7212):774-778

76. Etheredge LM. A rapid-learning health system. Health Aff (Millwood). 2007;26(2):w107-w118.
77. Institute of Medicine. Learning Healthcare System Concepts v. 2008. Washington, DC: Institute of Medicine 2008.

78. McClellan MB, McGinnis MJ, Nabel EG, Olsen LM. Evidence-Based Medicine and the Changing Nature of Health Care: 2007 IOM Annual Meeting Summary. Washington, DC: The National Academies Press; 2008.

79. Glasgow RE, Green LW, Klesges LM, et al. External validity: we need to do more. Ann Behav Med. 2006;31(2):105-108.

80. Green LW, Glasgow RE, Atkins D, Stange K. Making evidence from research more relevant, useful, and actionable in policy, program planning, and practice slips "twixt cup and lip". Am J Prev Med. 2009;37(6)(Suppl 1):S187-S191.

81. Croyle RT. The National Cancer Institute's transdisciplinary centers initiatives and the need for building a science of team science. Am J Prev Med. 2008;35(2)(Suppl):S90-S93.

82. Hall KL, Feng AX, Moser RP, Stokols D, Taylor BK. Moving the science of team science forward: collaboration and creativity. Am J Prev Med. 2008;35(2)(Suppl):S243-S249.

83. Hall KL, Stokols D, Stipelman BA, et al. Assessing the value of team science: a study comparing center- and investigator-initiated grants. Am J Prev Med. 2012;42(2):157-163.

84. Holmes JH, Lehman A, Hade E, et al. Challenges for multilevel health disparities research in a transdisciplinary environment. Am J Prev Med. 2008;35(2)(Suppl):S182-S192.

85. Syme SL. The science of team science: assessing the value of transdisciplinary research. Am J Prev Med. 2008;35(2)(Suppl):S94-S95.

86. Ernst C, Chrobot-Mason D. Boundary Spanning Leadership. New York, NY: McGraw-Hill; 2011.

87. Stange KC, Aungst $H$, Ruhe M, et al. Boundary spanning and health: invitation to a learning community. Lond J Prim Care. 2012;4(2):109-115.

88. Williams PT. The competent boundary spanner. Public Adm. 2002;80(1):103-124.

89. Hanleybrown F, Kania J, Kramer M. Channeling change: making collective impact work. Stanford Soc Innov Rev. 2012. http://partnership2012.com/download/Collective\%20Impact\%20II.pdf. Accessed Jun 14, 2013.

90. Kanaan SB, National Committee on Vital Health Statistics. The Community as a Learning System for Health: Using Local Data To Improve Local Health. 2011 ed. Washington, DC: US Department of Health and Human Services; 2012.

91. National Quality Forum. Multiple chronic conitions measurement framework. 2012. http://www.qualityforum.org/Projects/Multiple_Chronic_Conditions_Measurement_Framework.aspx. Accessed December 24, 2013.

92. Weick K. Sensemaking in Organizations. Thousand Oaks, CA: Sage Publications; 1995.

93. Weick KE, Sutcliffe KM. Managing the Unexpected. San Francisco, CA: Jossey-Bass; 2001.

94. Green LW, Glasgow RE. Evaluating the relevance, generalization, and applicability of research: issues in external validation and translation methodology. Eval Health Prof. 2006;29(1):126-153.

95. Patient Centered Outcomes Research Institute. Mission and vision. http://www.pcori.org/about-us/mission-and-vision/. Accessed Aug 3, 2013.

96. National Research Council (US) Committee on A Framework for Developing a New Taxonomy of Disease. Toward Precision Medicine: Building a Knowledge Network for Biomedical Research and a New Taxonomy of Disease. Washington, DC: National Academy Press; 2011.

97. Soubhi H, Bayliss EA, Fortin M, et al. Learning and caring in communities of practice: using relationships and collective learning to improve primary care for patients with multimorbidity. Ann Fam Med. 2010;8(2):170-177.

98. Kempshall N. The care of patients with complex long-term conditions. Br J Community Nurs. 2010;15(4):181-187.

99. Kathol RG, Kathol MH. The need for biomedically and contextually sound care plans in complex patients. Ann Intern Med. 2010;153(9):619-620, author reply 620. 